\title{
Progression of functional limitations in relation to physical activity: a life course approach
}

\author{
Mikaela B. von Bonsdorff • Taina Rantanen
}

Received: 5 August 2010 / Accepted: 20 August 2010 /Published online: 30 August 2010

(C) European Group for Research into Elderly and Physical Activity (EGREPA) 2010

\begin{abstract}
In this minireview, we summarize the research results to date on the progression of functional limitations and the role of physical activity during the life course in preventing risk factor accumulation. In addition, socioeconomic and health disparities play a role in the development process of functional limitation throughout life. We discuss the potential role of physical activity in alleviating this process. Functional limitations usually develop gradually over an extended period of time while the level of physical functioning varies greatly already from midlife onwards. Current research strongly suggests that physical activity has a beneficial effect on functional limitations at different life stages on the population level. However, the potential impact of physical activity in alleviating the effects caused by socioeconomic disparities is inconsistent. Research findings are also conflicting on the extent of the effect of physical activity among certain subsets of the population, such as obese persons. Although the benefits of physical activity on physical impairments and functioning among the adult population have been confirmed, the number of adults who are physically active is too low and, for the majority, physical activity declines with older age. Thus, detailed research evidence is needed for designing effective preventive interventions starting from earlier ages and continuing throughout the lifespan across different subgroups in the population.
\end{abstract}

Keywords Functional limitation · Physical activity - Life course $\cdot$ Accumulation $\cdot$ Aging

M. B. von Bonsdorff $(\bowtie) \cdot$ T. Rantanen

Gerontology Research Centre, Department of Health Sciences,

University of Jyväskylä,

P.O. Box 35, Viveca 40014, Finland

e-mail: mikaela.vonbonsdorff@jyu.fi

\section{Introduction}

Functional limitations, the focus of the present minireview, are defined as restrictions in performing vital situation-free physical actions needed in everyday life [1]. Functional limitation is an intermediate step on the pathway leading from pathology and impairment via functional limitations to subsequent disability $[1,2]$. It is a dynamic process in which persons develop functional difficulties, e.g., in walking, from which they might temporarily recover but which later recur, or they may recover but later exhibit a new functional limitation. Here, we focus on physical functioning such as mobility measured as the ability to walk [3] or as perceived difficulties in walking [4] and on physical performance measures such as climbing stairs or lifting heavy objects [5]. Often when evaluating the functioning of older people, disability is used as a measure. However, disability is an outcome which is dependent on the environment, not just the physical capability of the person. Thus, using functional limitation as a more proximal outcome in the disablement process provides a more objective measure and can also help in investigating the consequences of disease and impairment [6].

Absence of functional limitations allows people to live independently, perform everyday tasks, and lead a socially active life [7]. For most young people, tasks such as walking or lifting boxes and bags are activities which can be performed without undue attention being devoted to them. However, with older age, managing these everyday activities becomes less self-evident. The level of physical functioning varies greatly already in midlife, with women being seriously disadvantaged compared to men [8]. With population aging, the interest of governments and individuals regarding the expected trends in physical functioning is very much driven by the wide-ranging effects that physical 
functioning has on the individual's ability to lead an independent life and the potential need of health and social care services $[8,9]$.

Physical activity is defined here as bodily movement that results from the contraction of skeletal muscle that increases energy expenditure above the basal level [10]. Physical exercise, including strength, endurance, and flexibility training, in turn is physical activity that is planned, structured, and repetitive in nature. Physical activity can vary from recreational exercise to everyday activities such as walking to the grocery store or gardening. Physical activity is a behavior that seems to track through the lifespan as Hirvensalo and Lintunen show in their review in this issue on page XXX. The level of physical activity has been shown to be linked with socioeconomic status throughout the lifespan. There is evidence of an association between social and psychological environments at different periods of life and health-related behaviors: for example, lower social class has been associated with physical inactivity in adolescence [11]. Physical activity in childhood and adolescence predicts both physical activity in adulthood [12, 13] and better health and well-being [14]. Similarly, persons who are physically active in midlife are more likely to continue being physically active in older age regardless of chronic diseases [15]. However, for the majority, physical activity declines with older age [16], partly due to the aging process, the deterioration of muscle tissue, and an increase in morbidity and the rate of functional decline [16-18]. The same trend can be seen among middle-aged persons as well.

Prospective studies have shown that midlife muscle strength tracks over to old age and predicts functional limitations and disability. People with higher muscle strength in midlife remain protected from old age disabilities regardless of various diseases which may develop over the years $[19,20]$. The benefits of strength training on muscle strength and functional limitations among older people have been confirmed in randomized controlled trials $[21,22]$. Several well-conducted prospective studies have shown that physical activity protects against the development of chronic conditions such as cardiovascular diseases, arthritis, diabetes, and obesity [23, 24], which, in turn, have been shown to be important risk factors for functional limitations $[7,25,26]$.

In the context of life course epidemiology [27], decline in functioning can either happen gradually over a long time period due to, e.g., disuse of muscles [28, 29] or it might be catastrophic due to a sudden event such as an accident [30]. We focus here on the chronic gradual decline in physical functioning which is affected by events starting pre-natally and continuing after birth through adult and old age. Using the life course perspective, we summarize the research results to date on the progression of functional limitations and the role of physical activity during the life course in preventing risk factor accumulation. In addition, socioeconomic and health disparities play a role in the development of functional limitation throughout life. We discuss the potential role of physical activity in alleviating this process.

\section{Functional limitations and aging}

Defining functional limitation may be based on objectively measured test results with validated reference values or on an individual's perception of specific difficulties or changes in performing the task in question. Physical performance tests typically measure upper or lower extremity functioning and can be single tests or test batteries that consist of several individual tests [6]. The most often used individual tests comprise of objective walking tests measuring habitual or maximal walking speed over certain distances $[4,31]$ or selfreported difficulties in walking different distances $[4,32]$. The advantage of using physical performance tests is that they are objective; however, they are more difficult to carry out with large study samples. Self-report data on difficulties in walking are easier to gather, but have the disadvantage that individual's perceptions on their ability to walk certain distances or what they consider mobility difficulties can differ widely.

Functional limitations such as walking difficulties increase with age. A population-based Finnish study on persons aged 55 and over found that a third of women and a fifth of men could not reach a walking speed of $1.2 \mathrm{~m} / \mathrm{s}$ [32]. In the UK, $8 \%$ of women and $9 \%$ of middle-aged men reported having much difficulty or being unable to walk a quarter of a mile [33]. In the US, among 70- to 79-year-old communitydwelling persons who did not have mobility limitations at baseline, $34.3 \%$ of men and $47.4 \%$ of women developed mobility limitations over a 4.5-year follow-up [34].

In line with the disablement process [1], functional limitations such as decline in mobility can be caused by pathology such as chronic diseases [35] and impairments such as decline in muscle strength and balance [36]. On the other hand, decline in mobility is a strong predictor for subsequent adverse outcomes such as disability and dependence in old age $[3,37]$. Further, a prospective study using the National Longitudinal Surveys data showed that functional limitations were likely to co-occur so that severe limitations in walking increased the probability of having difficulties in climbing stairs among young and older women [38].

\section{The progression of functional limitations and physical activity during the life course}

The gradual development of functional limitations over an extended period of time is affected by natural age-related 
decline in physiological and biological properties such as decline in muscle strength and mass, which starts already in midlife [39], thus increasing the risk for decline in physical functioning later in life [36, 40]; see Fig. 1. Recently, it has been reported that preclinical signs precede emerging mobility limitation [41, 42]. A person with preclinical signs does not report difficulties in walking certain distances but has modified the task, e.g., reduced the walking pace, rest at intervals, or uses a walking aid [41, 43]. By optimizing the remaining abilities, a person can postpone potential problems in functioning and continue performing everyday activities. However, eventually with declining physical functioning, difficulties are increasingly encountered first with the most demanding physical tasks such as running or walking long distances and later on with easier tasks as well. The magnitude of difficulties grows with declining functioning and with multiple functional limitations.

Arthritis, a chronic inflammation of one or more joints, is one of the leading risk factors for functional limitations among adults. By the year 2030, about a quarter of the US adult population is projected to suffer from arthritis [44]. With older age, the growing prevalence of chronic diseases such as arthritis accelerates the natural age-related decline in physical functioning [23]. A prospective study using data from the Health and Retirement Study showed that persons who had arthritis at the age of 50 to 62 had a higher risk of developing difficulties in mobility over a 10 -year follow-up compared to those who did not suffer from arthritis [35]. Similarly, in an elderly cohort from the Framingham Study, the risk for mobility limitations was twofold for those with arthritis compared to those free from arthritis [45].

On the population level, prospective studies have found that higher level of physical activity from midlife onward decreases the risk of functional limitations in old age [46, 47] and other potential adverse outcomes such as need for care at the end of life [48]. For example, Sun et al. [46] showed in their recent prospective study on a large group of middle-aged nurses that higher physical activity level in midlife predicted successful survival in old age, an outcome that also included physical functioning. Evidence from randomized controlled trials on the positive effect of physical activity in decreasing functional limitations, e.g., among persons diagnosed with arthritis is amounting [23, 49]. However, intervention studies on promoting physical activity and testing the long-term benefits on functional limitations are rare. It is not really possible to carry through a trial targeting a behavior change in a controlled way with a follow-up lasting several decades. In our laboratory, we carried out a community-based effectiveness intervention on the benefits of physical activity counseling for mobility among older people with a follow-up extending over 3.5 years. The results showed that a single physical activity counseling session with a physiotherapist followed up by phone contact every 4 months for 2 years prevented mobility limitation [50].
Fig. 1 Examples of functional limitation development during the life course. Modified from Kuh [84]

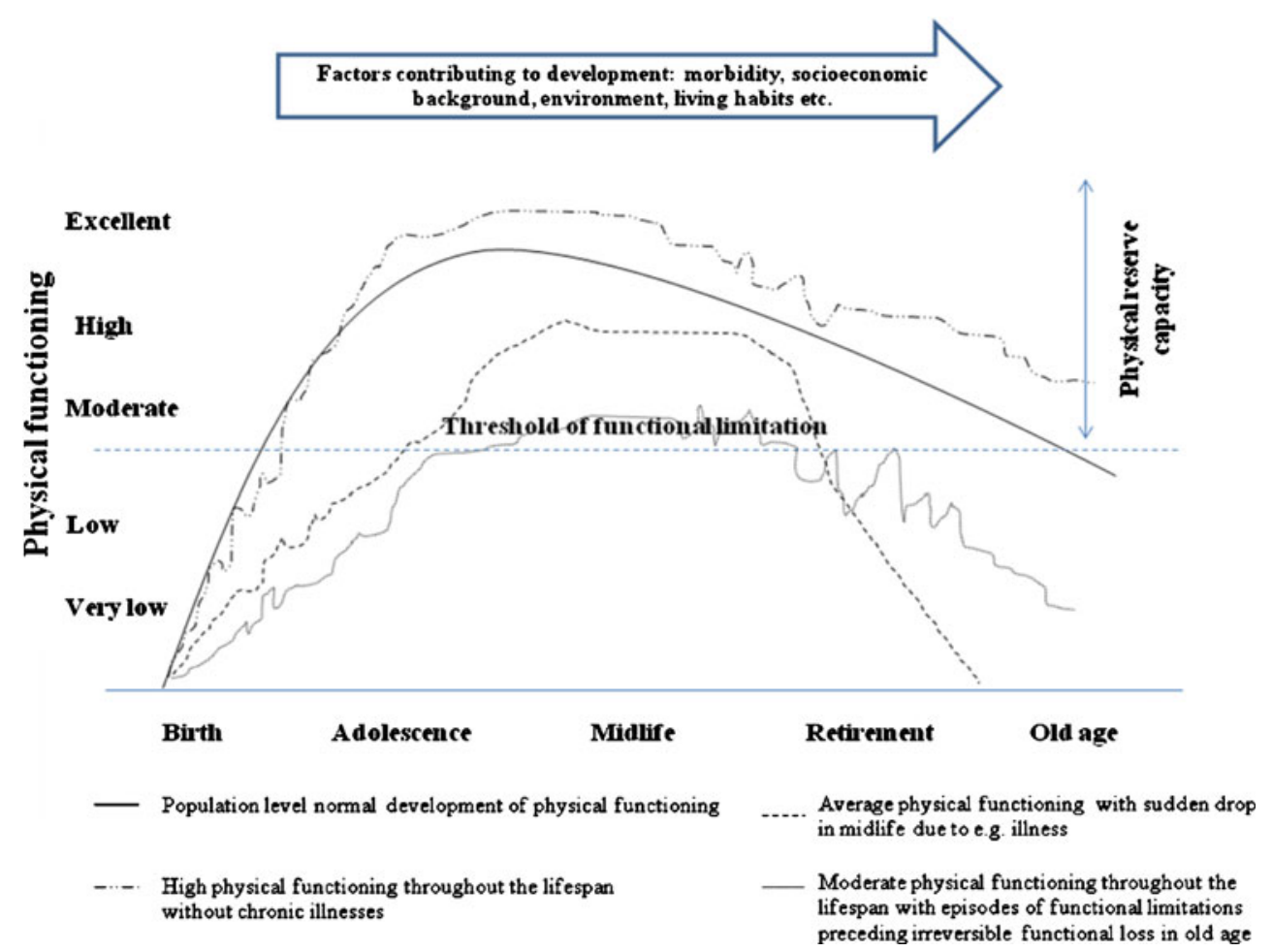


The vicious circle of obesity, physical activity, and functional limitations

Obesity, defined as abnormal fat accumulation in adipose tissue and a body mass index over 30, has markedly increased during recent decades and is now a public health problem worldwide [51]. WHO has estimated that by the year 2015 there will be about 700 million obese persons in the world [52]. Today, obesity has been found to have an earlier onset when comparing the baby boomer and earlier born so-called silent generations [53]. The adverse health and functional effects of obesity have been widely studied. For example, Stenholm et al. showed in their 22-year follow-up that high body mass index in midlife, especially when combined with physical impairments, was a strong predictor of walking limitation in old age [25]. The risk for functional limitations is further elevated by the expanding prevalence of obesity, which in turn increases the prevalence of simultaneously occurring debilitating diseases such as arthritis [53].

In spite of the encouraging results on the potential that physical activity has in ameliorating functional limitations or postponing them to later life on the population level, the results for obese persons are inconsistent [54-58]. Brach et al. showed with data from a 14-year follow-up to a walking intervention trial that consistent physical activity compensated for the detrimental influence of obesity among older community-dwelling women. In the study, women who had always been physically active and obese had a lower risk for functional decline than persons who were never active and always obese [54]. However, a prospective study on the Health, Aging and Body Composition study data, including 70- to 79-year-old participants, showed that a healthy lifestyle including physical activity could not overcome the effect that obesity had on the risk for mobility limitations [57]. A recent 12-month randomized controlled trial by Manini et al. showed that a moderate intensity exercise intervention improved 400-m walking speed for the non-obese participants but failed to do so among the obese participants; however, for both groups the Short Physical Performance Battery score increased [58]. In another trial among African American women with mobility disabilities and severe obesity, an intervention including monthly participation in an exercise support group with telephone coaching increased the level of physical activity and decreased body weight but did not have a significant effect on mobility limitations [59].

The vicious circle of functional limitations, obesity, and muscle strength probably starts to develop very early on in life [60], and physical activity plays an important role in that equation. The order of causality between physical inactivity and obesity is hard to determine because not only is obesity a potential cause of physical inactivity but physical inactivity is also an important risk factor for obesity. All in all, the interrelationship between obesity and physical activity on health outcomes is complex [34]. To date, little attention has been given to the perceived constraints on physical activity among older obese persons, which were in a recent study reported to include comorbidities, tiredness, pain, negative experiences regarding exercise, and fear of falling and injuring oneself [61].

\section{Physical activity and socioeconomic disparities in functional limitations}

Socioeconomic status throughout the lifespan, comprising such factors as education, income, and occupation, has been linked to the prevalence of diseases, functional decline, frailty, and mortality [62-64]. From a life course perspective, it may be hypothesized that adverse social and psychosocial environments throughout and across the lifespan may compromise individual behavioral capital [65], in turn influencing health-related behaviors. Behavioral capital has been defined by Schooling and Kuh as "the accumulation of positive individual attributes" [66] that could affect educational aspirations as well as the development of health behaviors such as physical activity.

Socioeconomic differences are expressed very early on in life. Parents from a lower social class are more likely to have babies with low birth weight [67]. Low birth weight is related not just to disadvantaged social conditions in childhood and adulthood [68] but also to a higher incidence of chronic diseases and functional limitations [69] and to grip strength independent of body size or social class in adulthood [70, 71]. Guralnik et al. [72] showed on the basis of the 1946 British birth cohort study data that socioeconomic status in adolescence predicted physical functioning in midlife. In their multivariate analysis, father's low occupational status was associated with low function and mother's higher education with high function at the age of 53 years when several measures of childhood deprivation were controlled for.

Prospective studies on older persons have shown that higher income and education decrease the risk for functional limitations [73, 74]; however, the results are not entirely consistent [75]. Research findings on the potential impact of lifestyle factors in diluting the effect that socioeconomic and environmental disadvantage has on functional limitations are few and inconsistent. Britton et al. [76], using data from the Whitehall II study on middleaged London-based civil servants, showed that a healthy lifestyle in midlife compensated for a disadvantaged start to life. In that study, midlife socioeconomic position was a strong predictor of successful aging and factors such as increased exercise, a healthy diet, and no smoking 
attenuated the harmful effect of the early and midlife social, behavioral, and psychosocial factors. However, in a 5-year Danish follow-up study on 75-year-old men and women, physical activity in old age did not reverse functional decline among those with cumulative poor material wealth throughout the life course [43].

\section{Discussion}

This review summarizes the evidence to date on the progression of functional limitation during the life course and of the potential that physical activity during different life stages has on reversing, retarding, or preventing the process of declining physical functioning. Although a limited number of studies have addressed the development of functional limitations from early age onwards, there is evidence that decline in physical functioning usually starts early in life and gradually progresses alongside the normal aging process. Moreover, the results strongly indicate a beneficial effect of physical activity on functional limitations at different life stages on the population level. However, the results are inconsistent regarding the potential impacts that healthy living habits such as physical activity have in alleviating the effects of socioeconomic disparities. Research findings are also conflicting on the extent of the effect that physical activity has among certain subsets of the population, such as obese persons. The discrepancy might partly be due to the complicated and intertwined nature of the role of the social and behavioral environment in connection with the development of functional limitations and physical activity at different life stages. However, the inconsistencies referred to above might also reflect gender differences, heterogeneity in measuring socioeconomic status, and selective dropout from the study $[43,76]$.

The evidence from randomized controlled trials conducted on older persons with varying degrees of frailty and chronic diseases such as osteoarthritis shows that exercise decreases physical impairments and functional limitations [21]. The mechanism whereby physical activity hinders and slows down the progression of functional limitations is most likely largely explained by the increased strength, aerobic capacity, and improved balance that results from increased exercise in spite of underlying chronic diseases in older age. There is evidence from prospective studies that physical activity can hinder functional limitations among obese persons. However, the evidence from randomized controlled exercise trials remains scarce and inconsistent. Furthermore, few randomized controlled trials have specifically investigated the effect of physical activity on persons with, e.g., socioeconomic disadvantages present at different stages throughout the life course. In particular, more evidence on persons with diverse back- grounds and living environments would help to clarify the relation between physical activity and the development of functional limitations.

With respect to analyzing the effects of earlier life events in the accumulation of functional limitations and physical activity, there are methodological challenges that need to be considered. Prospective data are needed to avoid reverse causation, which in the present research context would mean that functional limitation hinders a person from being physically active. When investigating the accumulation of functional limitations in relation to physical activity, we need to take into account the healthy exerciser effect in that persons with deteriorating health may be assumed to be less likely to be physically active [77]. At the same time, it is plausible that healthy persons who develop health problems are likely to stop exercising due to increased morbidity [78, 79]. Furthermore, the effect of genes in this equation needs to be investigated more closely, as Kujala states on page $\mathrm{XXX}$ of this issue. When examining events that take place over a prolonged period, with several intervening factors the ultimate order in which the events occur is often complex and less self-evident. Randomized controlled trials provide the best evidence on the effect of physical activity on functional limitations; however, because the progression of functional limitation is a slow ongoing process, very long intervention times would be needed and thus such trials cannot realistically be carried out.

\section{Implications for research}

In order to study the effect that aging has on the development of functional limitations from a truly life course perspective, we would need extensive populationbased prospective studies with follow-up times stretching over decades. Currently, no representative data, where the same individuals have been followed up from birth to very old age, are available, and thus researchers are compelled to use data that have been collected over shorter periods of time. This is, however, set to change as the participants in large datasets throughout the world, who have been followed up from a very early age, reach old age.

From a life course perspective, we know relatively little about the progress of functional limitations from very early age to old age. For example, are there certain critical periods or sensitive times during which the risk of functional limitation increases? Moreover, are there certain periods in which increasing physical activity is more effective in combating the progress of functional limitations?

Although inactive lifestyles are on the increase, there are also groups of inactive persons who would like to be active but lack the resources for doing so. The unmet need for 
physical activity in old age [80] should be addressed, and these persons are potential candidates for physical activity interventions. Given that the oldest age groups are the ones that are currently the fastest growing [81], we need to understand that tackling functional limitations early on and focusing on timely prevention could have far-reaching effects for the aging population in the years to come. Thus, a life course approach should be used when planning interventions for preventing functional limitations [35]. Interventions should also be aimed at younger age groups $[82,83]$. In addition, detailed research evidence is needed in order to assess effective means of prevention starting from earlier ages and extending throughout the lifespan across different subgroups in the population.

Acknowledgments This research was funded by the Academy of Finland.

\section{References}

1. Verbrugge LM, Jette AM (1994) The disablement process. Soc Sci Med 38:1-14

2. Nagi SZ (1976) An epidemiology of disability among adults in the United States. Milbank Mem Fund Q Health Soc 54:439-467

3. Guralnik JM, Ferrucci L, Simonsick EM, Salive ME, Wallace RB (1995) Lower-extremity function in persons over the age of 70 years as a predictor of subsequent disability. N Engl J Med 332:556-561

4. Rantanen T, Guralnik JM, Ferrucci L, Leveille S, Fried LP (1999) Coimpairments: strength and balance as predictors of severe walking disability. J Gerontol A Biol Sci Med Sci 54:172-176

5. Guralnik JM, Branch LG, Cummings SR, Curb JD (1989) Physical performance measures in aging research. J Gerontol 44:141-146

6. Guralnik JM, Ferrucci L (2003) Assessing the building blocks of function: utilizing measures of functional limitation. Am J Prev Med 25(3 Suppl 2):112-121

7. Guralnik JM, LaCroix AZ, Abbott RD, Berkman LF, Satterfield S, Evans DA, Wallace RB (1993) Maintaining mobility in late life. I. Demographic characteristics and chronic conditions. Am J Epidemiol 137:845-857

8. Kuh D, Bassey EJ, Butterworth S, Hardy R, Wadsworth ME, Musculoskeletal Study Team (2005) Grip strength, postural control, and functional leg power in a representative cohort of British men and women: associations with physical activity, health status, and socioeconomic conditions. J Gerontol A Biol Sci Med Sci 60:224-231

9. Fried TR, Bradley EH, Williams CS, Tinetti ME (2001) Functional disability and health care expenditures for older persons. Arch Intern Med 161:2602-2607

10. Caspersen CJ (1989) Physical activity epidemiology: concepts, methods, and applications to exercise science. Exerc Sport Sci Rev 17:423-473

11. Tammelin T, Nayha S, Laitinen J, Rintamaki H, Jarvelin MR (2003) Physical activity and social status in adolescence as predictors of physical inactivity in adulthood. Prev Med 37:375381

12. Telama R, Yang X (2000) Decline of physical activity from youth to young adulthood in Finland. Med Sci Sports Exerc 32:16171622
13. Tammelin T, Nayha S, Hills AP, Jarvelin MR (2003) Adolescent participation in sports and adult physical activity. Am J Prev Med 24:22-28

14. Sacker A, Cable N (2006) Do adolescent leisure-time physical activities foster health and well-being in adulthood? Evidence from two British birth cohorts. Eur J Public Health 16:332336

15. Hirvensalo M, Lintunen T, Rantanen T (2000) The continuity of physical activity - a retrospective and prospective study among older people. Scand J Med Sci Sports 10:37-41

16. Bijnen FC, Feskens EJ, Caspersen CJ, Mosterd WL, Kromhout D (1998) Age, period, and cohort effects on physical activity among elderly men during 10 years of follow-up: the Zutphen Elderly Study. J Gerontol A Biol Sci Med Sci 53:235-241

17. Bortz WM 2nd (2002) A conceptual framework of frailty: a review. J Gerontol A Biol Sci Med Sci 57:283-288

18. Rantanen T, Guralnik JM, Sakari-Rantala R, Leveille S, Simonsick EM, Ling S, Fried LP (1999) Disability, physical activity, and muscle strength in older women: the Women's Health and Aging Study. Arch Phys Med Rehabil 80:130-135

19. Rantanen T, Guralnik JM, Foley D, Masaki K, Leveille S, Curb JD, White L (1999) Midlife hand grip strength as a predictor of old age disability. JAMA 281:558-560

20. Rantanen T, Masaki K, Foley D, Izmirlian G, White L, Guralnik JM (1998) Grip strength changes over 27 yr in Japanese-American men. J Appl Physiol 85:2047-2053

21. Keysor JJ, Jette AM (2001) Have we oversold the benefit of late-life exercise? J Gerontol A Biol Sci Med Sci 56:412-423

22. Liu CJ, Latham N (2009) Progressive resistance training for improving physical function in older adults. Cochrane Database Syst Rev (3):CD002759

23. van Dijk GM, Dekker J, Veenhof C, van den Ende CH, Carpa Study Group (2006) Course of functional status and pain in osteoarthritis of the hip or knee: a systematic review of the literature. Arthritis Rheum 55:779-785

24. Gill JM, Cooper AR (2008) Physical activity and prevention of type 2 diabetes mellitus. Sports Med 38:807-824

25. Stenholm S, Sainio P, Rantanen T, Koskinen S, Jula A, Heliovaara M, Aromaa A (2007) High body mass index and physical impairments as predictors of walking limitation 22 years later in adult Finns. J Gerontol A Biol Sci Med Sci 62:859-865

26. Alley DE, Chang VW (2007) The changing relationship of obesity and disability, 1988-2004. JAMA 298:2020-2027

27. Kuh D, Ben-Shlomo Y, Lynch J, Hallqvist J, Power C (2003) Life course epidemiology. J Epidemiol Community Health 57:778-783

28. Blane D, Netuveli G, Stone J (2007) The development of life course epidemiology. Rev Épidémiol Santé Publique 55:31-38

29. Davis Smith J (2004) Civic service in Western Europe. Nonprof Volunt Sec Q 33:64-78

30. Guralnik JM, Ferrucci L, Balfour JL, Volpato S, Di Iorio A (2001) Progressive versus catastrophic loss of the ability to walk: implications for the prevention of mobility loss. J Am Geriatr Soc 49:1463-1470

31. Studenski S, Perera S, Wallace D, Chandler JM, Duncan PW, Rooney E, Fox M, Guralnik JM (2003) Physical performance measures in the clinical setting. J Am Geriatr Soc 51:314-322

32. Sainio P, Koskinen S, Heliovaara M, Martelin T, Harkanen T, Hurri H, Miilunpalo S, Aromaa A (2006) Self-reported and test-based mobility limitations in a representative sample of Finns aged 30+. Scand J Public Health 34:378-386

33. Melzer D, Gardener E, Guralnik JM (2005) Mobility disability in the middle-aged: cross-sectional associations in the English Longitudinal Study of Ageing. Age Ageing 34:594-602

34. Manini TM, Pahor M (2009) Physical activity and maintaining physical function in older adults. Br J Sports Med 43:28-31 
35. Covinsky KE, Lindquist K, Dunlop DD, Gill TM, Yelin E (2008) Effect of arthritis in middle age on older-age functioning. J Am Geriatr Soc 56:23-28

36. Rantanen T, Guralnik JM, Ferrucci L, Penninx BW, Leveille S, Sipila S, Fried LP (2001) Coimpairments as predictors of severe walking disability in older women. J Am Geriatr Soc 49:21-27

37. Cesari M, Kritchevsky SB, Penninx BW, Nicklas BJ, Simonsick EM, Newman AB, Tylavsky FA, Brach JS, Satterfield S, Bauer DC, Visser M, Rubin SM, Harris TB, Pahor M (2005) Prognostic value of usual gait speed in well-functioning older people - results from the health, aging and body composition study. J Am Geriatr Soc 53:1675-1680

38. Long JS, Pavalko EK (2004) The life course of activity limitations: exploring indicators of functional limitations over time. J Aging Health 16:490-516

39. Frontera WR, Hughes VA, Fielding RA, Fiatarone MA, Evans WJ, Roubenoff R (2000) Aging of skeletal muscle: a 12-yr longitudinal study. J Appl Physiol 88:1321-1326

40. Visser M, Goodpaster BH, Kritchevsky SB, Newman AB, Nevitt M, Rubin SM, Simonsick EM, Harris TB (2005) Muscle mass, muscle strength, and muscle fat infiltration as predictors of incident mobility limitations in well-functioning older persons. J Gerontol A Biol Sci Med Sci 60:324-333

41. Fried LP, Bandeen-Roche K, Chaves PH, Johnson BA (2000) Preclinical mobility disability predicts incident mobility disability in older women. J Gerontol A Biol Sci Med Sci 55:43-52

42. Manty M, Heinonen A, Leinonen R, Tormakangas T, SakariRantala R, Hirvensalo M, von Bonsdorff MB, Rantanen T (2007) Construct and predictive validity of a self-reported measure of preclinical mobility limitation. Arch Phys Med Rehabil 88:11081113

43. Avlund K, Damsgaard MT, Osler M (2004) Social position and functional decline among non-disabled old men and women. Eur J Public Health 14:212-216

44. Hootman JM, Helmick CG (2006) Projections of US prevalence of arthritis and associated activity limitations. Arthritis Rheum 54:226-229

45. Guccione AA, Felson DT, Anderson JJ, Anthony JM, Zhang Y, Wilson PW, Kelly-Hayes M, Wolf PA, Kreger BE, Kannel WB (1994) The effects of specific medical conditions on the functional limitations of elders in the Framingham Study. Am J Public Health 84:351-358

46. Sun Q, Townsend MK, Okereke OI, Franco OH, Hu FB, Grodstein F (2010) Physical activity at midlife in relation to successful survival in women at age 70 years or older. Arch Intern Med 170:194-201

47. Hillsdon MM, Brunner EJ, Guralnik JM, Marmot MG (2005) Prospective study of physical activity and physical function in early old age. Am J Prev Med 28:245-250

48. von Bonsdorff MB, Rantanen $\mathrm{T}$, Leinonen R, Kujala UM, Tormakangas T, Manty M, Heikkinen E (2009) Physical activity history and end-of-life hospital and long-term care. J Gerontol A Biol Sci Med Sci 64:778-784

49. Ettinger WH Jr, Burns R, Messier SP, Applegate W, Rejeski WJ, Morgan T, Shumaker S, Berry MJ, O'Toole M, Monu J, Craven T (1997) A randomized trial comparing aerobic exercise and resistance exercise with a health education program in older adults with knee osteoarthritis. The Fitness Arthritis and Seniors Trial (FAST). JAMA 277:25-31

50. Manty M, Heinonen A, Leinonen R, Tormakangas T, Hirvensalo M, Kallinen M, Sakari R, von Bonsdorff MB, Heikkinen E, Rantanen T (2009) Long-term effect of physical activity counseling on mobility limitation among older people: a randomized controlled study. J Gerontol A Biol Sci Med Sci 64:83-89

51. Brown WV, Fujioka K, Wilson PW, Woodworth KA (2009) Obesity: why be concerned? Am J Med 122(4 Suppl 1):4-11
52. World Health Organization. Fact sheet: obesity and overweight. World Health Organization. Available at http://www.who.int/ mediacentre/factsheets/fs311/en/. Accessed 4 August 2010

53. Leveille SG, Wee CC, Iezzoni LI (2005) Trends in obesity and arthritis among baby boomers and their predecessors, 1971-2002. Am J Public Health 95:1607-1613

54. Brach JS, VanSwearingen JM, FitzGerald SJ, Storti KL, Kriska AM (2004) The relationship among physical activity, obesity, and physical function in community-dwelling older women. Prev Med 39:74-80

55. He XZ, Baker DW (2004) Body mass index, physical activity, and the risk of decline in overall health and physical functioning in late middle age. Am J Public Health 94:1567-1573

56. Lang IA, Guralnik JM, Melzer D (2007) Physical activity in middle-aged adults reduces risks of functional impairment independent of its effect on weight. J Am Geriatr Soc 55:18361841

57. Koster A, Penninx BW, Newman AB, Visser M, van Gool CH, Harris TB, van Eijk JT, Kempen GI, Brach JS, Simonsick EM, Houston DK, Tylavsky FA, Rubin SM, Kritchevsky SB (2007) Lifestyle factors and incident mobility limitation in obese and non-obese older adults. Obesity (Silver Spring) 15:3122-3132

58. Manini TM, Newman AB, Fielding R, Blair SN, Perri MG, Anton SD, Goodpaster BC, Katula JA, Rejeski WJ, Kritchevsky SB, Hsu FC, Pahor M, LIFE Research Group (2010) Effects of exercise on mobility in obese and nonobese older adults. Obesity (Silver Spring) 18:1168-1175

59. Rimmer JH, Rauworth A, Wang E, Heckerling PS, Gerber BS (2009) A randomized controlled trial to increase physical activity and reduce obesity in a predominantly African American group of women with mobility disabilities and severe obesity. Prev Med 48:473-479

60. Stenholm S (2007) Obesity as a risk factor for walking limitation in older Finnish men and women. National Public Health Institute, Turku

61. Sallinen J, Leinonen R, Hirvensalo M, Lyyra TM, Heikkinen E, Rantanen T (2009) Perceived constraints on physical exercise among obese and non-obese older people. Prev Med 49:506-510

62. Turrell G, Lynch JW, Leite C, Raghunathan T, Kaplan GA (2007) Socioeconomic disadvantage in childhood and across the life course and all-cause mortality and physical function in adulthood: evidence from the Alameda County study. J Epidemiol Community Health 61:723-730

63. Kuh D, Hardy R, Langenberg C, Richards M, Wadsworth ME (2002) Mortality in adults aged 26-54 years related to socioeconomic conditions in childhood and adulthood: post war birth cohort study. BMJ 325:1076-1080

64. Alvarado BE, Zunzunegui MV, Beland F, Bamvita JM (2008) Life course social and health conditions linked to frailty in Latin American older men and women. J Gerontol A Biol Sci Med Sci 63:1399-1406

65. Bartley M, Blane D, Montgomery S (1997) Health and the life course: why safety nets matter. BMJ 314:1194-1196

66. Schooling M, Kuh D (2002) A life course perspective on women's health behaviors. In: Kuh D, Hardy R (eds) A life course approach to women's health. Oxford University Press, Oxford, pp 279-303

67. Finch BK (2003) Socioeconomic gradients and low birth-weight: empirical and policy considerations. Health Serv Res 38:1819-1841

68. Bartley M, Power C, Blane D, Smith GD, Shipley M (1994) Birth weight and later socioeconomic disadvantage: evidence from the 1958 British cohort study. BMJ 309:1475-1478

69. Saigal S, Stoskopf B, Boyle M, Paneth N, Pinelli J, Streiner D, Goddeeris J (2007) Comparison of current health, functional limitations, and health care use of young adults who were born with extremely low birth weight and normal birth weight. Pediatrics 119:562-573 
70. Kuh D, Bassey J, Hardy R, Aihie Sayer A, Wadsworth M, Cooper C (2002) Birth weight, childhood size, and muscle strength in adult life: evidence from a birth cohort study. Am J Epidemiol 156:627-633

71. Sayer AA, Syddall HE, Gilbody HJ, Dennison EM, Cooper C (2004) Does sarcopenia originate in early life? Findings from the Hertfordshire cohort study. J Gerontol A Biol Sci Med Sci 59:930-934

72. Guralnik JM, Butterworth S, Wadsworth ME, Kuh D (2006) Childhood socioeconomic status predicts physical functioning a half century later. J Gerontol A Biol Sci Med Sci 61:694-701

73. Rautio N, Heikkinen E, Ebrahim S (2005) Socio-economic position and its relationship to physical capacity among elderly people living in Jyvaskyla, Finland: five- and ten-year follow-up studies. Soc Sci Med 60:2405-2416

74. Seeman TE, Charpentier PA, Berkman LF, Tinetti ME, Guralnik JM, Albert M, Blazer D, Rowe JW (1994) Predicting changes in physical performance in a high-functioning elderly cohort: MacArthur studies of successful aging. J Gerontol 49:97-108

75. Clark DO, Stump TE, Hui SL, Wolinsky FD (1998) Predictors of mobility and basic ADL difficulty among adults aged 70 years and older. J Aging Health 10:422-440

76. Britton A, Shipley M, Singh-Manoux A, Marmot MG (2008) Successful aging: the contribution of early-life and midlife risk factors. J Am Geriatr Soc 56:1098-1105
77. Wolinsky FD, Stump TE, Clark DO (1995) Antecedents and consequences of physical activity and exercise among older adults. Gerontologist 35:451-462

78. Fries JF (1996) Physical activity, the compression of morbidity, and the health of the elderly. J R Soc Med 89:64-68

79. Wannamethee SG, Shaper AG, Walker M (1998) Changes in physical activity, mortality, and incidence of coronary heart disease in older men. Lancet 351:1603-1608

80. Rantakokko M, Iwarsson S, Hirvensalo M, Leinonen R, Heikkinen E, Rantanen T (2010) Unmet physical activity need in old age. J Am Geriatr Soc 58:707-712

81. Kirkwood TB (2008) A systematic look at an old problem. Nature 451:644-647

82. Covinsky KE, Yaffe K, Lindquist K, Cherkasova E, Yelin E, Blazer DG (2010) Depressive symptoms in middle age and the development of later-life functional limitations: the long-term effect of depressive symptoms. J Am Geriatr Soc 58:551-556

83. Kuh D, Hardy R, Butterworth S, Okell L, Richards M, Wadsworth M, Cooper C, Sayer AA (2006) Developmental origins of midlife physical performance: evidence from a British birth cohort. Am J Epidemiol 164:110-121

84. Kuh D, New Dynamics of Ageing (NDA) Preparatory Network (2007) A life course approach to healthy aging, frailty, and capability. J Gerontol A Biol Sci Med Sci 62:717-721 